2

3

4

5

6

7

9

10

11

12

13

14

15

16

17

18

19

4

\title{
25-HYDROXYL-CHOLESTEROL BINDS AND ENHANCE ANTI-VIRAL EFFECTS OF ZEBRAFISH MONOMERIC C-REACTIVE PROTEINS
}

\author{
short title: zebrafish hydroxycholesterol-CRP
}

Melissa Bello-Perez ${ }^{2}$, Alberto Falco², Jose Antonio Encinar ${ }^{2}$, Beatriz Novoa ${ }^{3}$, Luis Perez ${ }^{2}$, Julio Coll ${ }^{*}$.

${ }^{1}$ Instituto Nacional Investigaciones y Tecnologías Agrarias y Alimentarias, Dpto. Biotecnología. INIA. Madrid, Spain.

${ }^{2}$ Instituto de Biología Molecular y Celular, Universidad Miguel Hernández (IBMC-UMH). Elche, Spain .

${ }^{3}$ Investigaciones Marinas.CSIC. Vigo, Spain

LP and JC contributed equally to this work.

* Corresponding author

Email address:

MB, melissa.bello@umh.es

AF,alber.falco@umh.es

JA, jant.encinar@umh.es

BN, beatriznovoa@,iim.csic.es

LP, luis.perez@umh.es

JC, juliocoll@,inia.es 


\section{Abstract}

32 C-reactive proteins (CRP) are among the faster acute-phase inflammation-responses coded by one gene in

33 humans (hcrp) and seven genes (crp1-7) in zebrafish (Danio rerio). In this study, preferential 25-

34 hydroxycholesterol (25HOCh) binding to zebrafish CRP1-7 compared to other lipids were predicted by in

35 silico docking and confirmed by solid-phase binding-assays. In addition, 25HOCh enhanced methyl-

36 betacyclodextrin-sensitive (Cholesterol-dependent) CRP1-7 anti-viral effects in a fine-tunned isoform-

37 dependent manner. In silico and structural studies suggested that the crosstalk between the anti-viral

38 enhancements of both 25HOCh and CRP1-7 were dependent on protein monomers rather than oligomers but

39 differred among isoforms. The presence of oxidized cholesterols in human atherosclerotic plaques amplifies

40 the importance that similar interactions may have for vascular and/or neurodegenerative diseases during viral

41 infections. In this context, the zebrafish model offers a genetic tool to further investigate how the expression

42 and functions of different CRP isoforms and/or transcript variants may be controlled.

44 Keywords: c-reactive protein; isoforms; 25-hydroxy-cholesterol; docking; zebrafish; SVCV 


\section{Introduction}

Previous studies have shown that in contrast to the one gene-coded human c-reactive protein (hCRP) [1], seven genes coded for CRP1-7 isoforms in zebrafish (Danio rerio) [2]. The hCRP are one of the most important clinical biomarkers for inflammation and most recently have been associated with relevant diseases such as those caused by cardiovascular and neurodegenerative disorders [3-5]. Circulating CRP molecules are planar oligomers of $\sim 25 \mathrm{KDa}$ monomers. The hCRP is pentameric (p-hCRP) while zebrafish CRP5 crystalizes as trimers [6]. It is not yet known whether or not other CRP1-7 isoforms are trimeric and what are their prevalent physiological conformation(s). On the other hand, some CRP1-7 isoform-dependent heterogeneous biological properties have been most recently described $[6,7]$.

The planar p-hCRP shows both lipid-recognition and functional-effector faces [5]. The recognition face binds phosphocholine heads exposed at the surface of prokaryotic/eukaryotic membranes in a $\mathrm{Ca}^{++}[8,9]$ and phospholipase $\mathrm{A}_{2}[10]$-dependent manner in damaged tissues [5]. Triggered by the $\mathrm{CRP}-\mathrm{Ca}^{++}-$ phosphocholine complexes, the functional-effector face binds C1q to activate the classical complement pathway, immunoglobulin Fc receptors to activate phagocytosis $[11,12]$ and other ligands to activate multiple cellular functions [10]. In order to accomplish all that variety of functions, hCRP shows, at least, 4 different conformations $[5,13]$ : i) Inactive serum-circulating $\mathrm{p}$-hCRP, which is present in low concentrations in healthy humans, increasing 100-1000-fold after inflammation, ii) Pro-inflammatory tissue-associated phCRP* [4], iii) Pro-inflammatory tissue-associated monomeric hCRP (m-hCRP) with wider ligand capacities which include cholesterol (Ch) [14-16] and iv) Disulphide-reduced m-hCRP which activates lymphoid and many other cells [5, 16-18]. Despite different oligomeric structures between p-hCRP and t-CRP5 [6], their protein hydrophobic profiles, two cysteine residues per monomer, $\mathrm{Ca}^{++}$-binding amino acids and location of phosphocholine (PC)-binding pockets, were highly conserved [19]. On the other hand, previous transcriptomic studies on crp1-7 genes demonstrated differential transcript expression in zebrafish tissues [2], in survivors of viral infection [20] and in mutants defective in adaptive immunity [21]. In addition, unexpected $\operatorname{crp} 1-7 / \mathrm{CRP} 1-7$ isoform-dependent anti-viral in vitro and in vivo activities have been described showing also that crp2/CRP2 and crp5/CRP5 transcripts/proteins were the most modulated during in vivo 


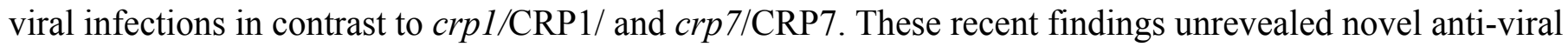

CRP1-7 direct or indirect activities in zebrafish which, to our knowledge, have not been described yet for

hCRP. All the similar properties mentioned above suggested analogous biological functions for $\mathrm{p}$-hCRP and

CRP1-7 [7], however, whether CRP1-7 isoforms do physiologically exist as different oligomeric structures,

conformations and/or become specialized in different ligand-binding or biological functions remains unexplored.

In this work, we focused by in silico and in vitro studies on the lipid-docking/binding, anti-viral activities and oligomeric forms of the CRP1-7 isoforms and CRP5 transcript variants of zebrafish. We have found that i) $\mathrm{Ca}^{++}$-independent docking/binding of CRP1-7 to Ch was preferred to other lipids, ii) HOChs were a preferential target for CRP1-7, specially for CRP1, iii) HOChs enhanced the anti-viral direct or indirect effects by zebrafish CRP1-7 in an isoform-dependent manner and iv) CRP2 / CRP5 and numerous CRP5 transcript variants have an stronger tendency to fold as trimers. The abundance of oxidized Chs in atherosclerotic plaques amplifies the importance that similar interactions may have for vascular diseases and neurodegenerative disorders during viral infections in humans [22-24]. The functional significance of the 


\section{Material and Methods}

\section{In silico docking predictions between zebrafish CRP1-7 and lipids}

The AutoDock Vina [26] included in the PyRx program package [27] was used to predict Gibbs free-

energy of docking $(\Delta \mathrm{G})$ of $60 \times 60 \times 60 \AA$ grids surrounding the CRP1-7 molecules. When required for

comparison purposes with experimental data, the output $\Delta \mathrm{G}$ energies were converted to constant inhibition

$(\mathrm{Ki})$ in molar concentrations $(\mathrm{M})$, by the formula $\mathrm{Ki}=\exp ([\Delta \mathrm{G} \times 1000] /[\mathrm{R} \times \mathrm{T}])(\mathrm{R}=1.98 \mathrm{cal} / \mathrm{mol}$, and $\mathrm{T}=$

$\left.298^{\circ} \mathrm{C}\right)[28]$. The predicted structures were visualized in PyRx and/or PyMOL (https://www.pymol.org/).

\section{Cell culture in EPC cell monolayers}

The epithelioma papulosum cyprinid (EPC) cells from fathead minnow fish (Pimephales promelas)

were obtained from the American Type Culture Collection (ATCC, Manassas, Vi, USA, code number CRL-

2872). EPC cell monolayers were grown at $26^{\circ} \mathrm{C}$ in a $5 \% \mathrm{CO}_{2}$ atmosphere in RPMI-1640 Dutch modified cell

culture medium (Gibco, UK) supplemented with 20 mM HEPES, 10 \% fetal bovine serum, FBS (Sigma, St.

Louis, USA), $1 \mathrm{mM}$ piruvate, $2 \mathrm{mM}$ glutamine, $50 \mu \mathrm{g} / \mathrm{ml}$ of gentamicin (Gibco) and $2 \mu \mathrm{g} / \mathrm{ml}$ of fungizone [21].

\section{Preparation of spring viremia carp virus (SVCV)}

The isolate 56/70 of Spring Viremia Carp Virus (SVCV) from carp C. carpio [29], recently renamed

Carp Sprivivirus [30], was replicated in EPC cell monolayers at $26^{\circ} \mathrm{C}$, in the cell culture media described

monolayers were clarified by centrifugation at $4000 \mathrm{~g}$ for $30 \mathrm{~min}$ and kept at $-80{ }^{\circ} \mathrm{C}$ until used [21].

\section{Estimation of the effects of methyl-betaciclodextrin (MBCD) in SVCV infectivity}

EPC cell monolayers treated for $2 \mathrm{~h}$ with different concentrations $(0-8 \mathrm{mM})$ of MBCD were incubated

with SVCV for $24 \mathrm{~h}$ and assayed for fluorescent focus forming units (ffu) (see later). The results were

non-treated with MBCD). To assay for viability, EPC cell monolayers treated with different concentrations 
percentage of viability calculated by the formula, absorbance of MBCD treated cells / absorbance of

130 untreated cells. Means and standard deviations $(n=2)$ were interpolated and smoothed by the cubic B-spline

131 method in Origin Pro 2017 (Northampton, MA, USA).

\section{Construction of recombinant pRSET-CRP1-7 for E.coli expression.}

The corresponding mRNA sequences of the CRP1-7 proteins [7] were used for the design, construction

and expression in E.coli. All the corresponding synthetic DNA sequences were cloned into the pRSET adding poly-histidine tails (polyH) at their C-terminal ends (GeneArt, Regensburg, Germany). The purified plasmids

were then transfected into E.coli BL21(DE3) and grown at $37^{\circ} \mathrm{C}$. The resulting recombinant bacteria from the

electrophoresis (PAGE) and Western blot were used to detect CRP1-7 expression.

\section{Construction of recombinant rCRP1, rCRP2, rCRP5, rCRP7 for insect expression}

containing the gp67 signal peptide + CRP1-7 + Flag (DYKDDDK) +6 x polyHis sequences (construct size of $\sim$

$3 \mathrm{Kbp}$ ) were synthesized and sub-cloned into the pFastBac $1^{\mathrm{TM}}$ baculovirus transfer vector (Invitrogen). The

pFastBac1 recombinants were transfected into DH10 Bac $^{\mathrm{TM}_{-}}$-competent $E$. coli cells and bacmids prepared

from selected E. coli clones. Next, recombinant baculoviruses were generated in Spodoptera frugiperda (Sf9)

$3 \%$ non-essential amino acids and $20 \mu \mathrm{g} / \mathrm{ml}$ gentamicin at $28^{\circ} \mathrm{C}$ [31] were co-transfected with bacmids and

baculovirus using Cellfectin II. Supernatants containing the recombinant baculoviruses were obtained $72 \mathrm{~h}$

post-transfection with titres of $\sim 10^{7} \mathrm{pfu} / \mathrm{ml}$.

For rCRP expression and purification, $500 \mathrm{ml}$ of $\mathrm{Sf} 9$ cell supernatants were harvested $72 \mathrm{~h}$ post-infection

152 Flag or $\mathrm{Ni}^{++}$columns equilibrated with $50 \mathrm{mM}$ Tris, $500 \mathrm{mM} \mathrm{NaCl}, 5 \%$ glycerol, $\mathrm{pH} 8.0$, eluted with $200 \mu \mathrm{g} / \mathrm{ml}$

153 of the Flag peptide or $150 \mathrm{mM}$ imidazole, dialyzed against equilibration buffer and kept at $-20^{\circ} \mathrm{C}$ until used.

154 Purified rCRP were loaded in 8-20\% SDS-polyacrylamide gels (BioRad), electrophoresed, and transferred to 
155

nitrocellulose membranes (Schleicher \& Schuell) to detect specific tag epitopes. The membranes were blocked with phosphate buffer saline-0.05\% Tween 20 with $4 \%$ skim milk, incubated with anti-poly-H monoclonal antibody MAb (Sigma) for $1 \mathrm{~h}$, and then with anti-mouse horseradish peroxidase-conjugated immunoglobulins (Sigma) and visualized with diaminobenzidine (DAB). Protein concentrations were determined using the bicinchoninic acid (BCA) method [32] and confirmed by PAGE with BSA as standard.

\section{Production of rabbit antibodies to recognize zebrafish CRP1-7 isoforms}

To detect CRP1-7 isoforms in lipid-binding assays and after PAGE by Western blotting, anti-CRP1-7 rabbit antibodies were raised (GenScript, Piscataway, NJ, USA) against 3 of the longest more conserved amino acid stretches such as peptide p1 ( ${ }^{18}$ SYVKLSPEKPLSLSAFTLC), peptide p2 ( ${ }^{189}$ DWDTIEYDVTGN) and peptide p3 ( ${ }^{129}$ RPGGTVLLGQDPDSYVGSFC). All p1, p2 and p3 were located at the CRP1-7 surface, as shown by PyMOL modelling of trimeric CRP5 $\pm \mathrm{Ca}^{++}$(4PBP.pdb and 4PBO.pdb, respectively) [6] (not shown). To reduce assay backgrounds, the anti-peptide antibodies were purified by affinity chromatography against the corresponding synthetic peptides coupled to CNBr-activated Sepharose. Only the affinity-purified anti-p3 antibodies bound purified insect-made rCRP2, rCRP5 and rCRP7 on Western blots under denaturing and non-denaturing conditions (Figure 1A) and recognized EPC cells transfected with pMCV1.4-crp2-7 by immunofluorescence (not shown).

\section{Binding of CRP1-7 to solid-phase lipids}

Binding of CRP1-7 to lipids were assayed in solid-phase 96-well plates (Nunc, Maxisorb) by modifying previously described methods [33]. Wells were coated to dryness with several concentrations of ethanol dissolved lipids and kept dried until used. To assay for CRP1-7 binding, the plates were first washed with $0.1 \mathrm{M}$ sodium borate, $1 \mathrm{mM} \mathrm{Ca}_{2} \mathrm{Cl}$ buffer, $\mathrm{pH} 8$, and then $0.5 \mu \mathrm{g} /$ well of rCRPs or 10-fold diluted ssCRP1-7 added in $50 \mu \mathrm{l}$ of the same buffer and incubated for $60 \mathrm{~min}$. After washing, bound CRP1-7 were detected with rabbit antip3 and peroxidase-labelled goat anti-rabbit IgG. Peroxidase was finally assayed with OPD as described before $[34,35]$. All the resulting data were interpolated and smoothed by the cubic B-spline method in Origin Pro 2017 (Northampton, MA, USA). 
A series of 15-mer peptides overlapping 5 amino acids of the CRP5 sequence were chemically

synthesized by adding an amino-terminal biotin molecule (Chiron Mimotopes, Victoria, Australia). The synthetic

183

184

185

186

187

188

189

190

191

192

193

194

195

196

197

198

pepscan peptides were diluted in distilled water to $4 \mathrm{mg} / \mathrm{ml}$ and kept frozen until use.

To perform the binding experiments, $2 \mu \mathrm{g}$ of $25 \mathrm{HOCh}$ were dissolved in $50 \mu \mathrm{l}$ of ethanol and dried into polystyrene wells of 96-well Nunc Maxisorb plates. After washing the plates with $0.1 \mathrm{M}$ borate buffer $\mathrm{pH} 8,1$ $\mathrm{mM} \mathrm{CaCl} 2$, pepscan peptides $(0.05 \mu \mathrm{g}$ in $50 \mu \mathrm{l})$ were added to each of the wells and incubated for 60 min. After washing, 1000-fold diluted peroxidase-labelled streptavidin were added and incubated for 30 min. After the last washing, OPD was used to detect the amount of peroxidase as described before [35].

To perform the in silico docking predictions, the best modelled CRP5 pepscan peptide sequences predicted in solution by the Mobyle program http://mobyle.rpbs.univ-paris-diderot.fr/cgi-

bin/portal.py\#forms::PEP-FOLD [36] were docked to all possible predicted conformations of 25HOCh. All the resulting docking data were interpolated and smoothed by the cubic B-spline method in Origin Pro 2017 (Northampton, MA, USA) and the data which best fitted pepscan binding selected for representation. Validation of such strategy was confirmed by the high correlation obtained among similarly modelled VHSV G protein pepscan 15-mer peptides and previously published binding data to labelled phosphatidylserine [37] and phosphatidylinositol-bisphosphate [38] (not shown).

\section{Preparation of pMCV1.4 plasmids coding for crp1-7}

Each of the chemically synthesized crp $1-7$ and green fluorescent protein $(g f p)$ genes was subcloned into the pMCV1.4 plasmid as described before [7]. The resulting pMCV1.4-crp1-7 and pMCV1.4-gfp plasmid constructs were used to transform E.coli DH5alpha, amplified and isolated with the Endofree Plasmid Midi purification Kit (Qiagen, Germany) according to manufacturer's instructions. Purified plasmid solutions containing $80-100 \%$ of plasmid DNA, as shown by agarose gel electrophoresis were stored at $-20{ }^{\circ} \mathrm{C}$.

\section{Preparation of CRP1-7 enriched supernatants}

To produce ml amounts of CRP1-7 enriched supernatants (ssCRP1-7), $60 \%$ confluent EPC cell monolayers in $25 \mathrm{~cm}^{2}$ bottles in $5 \mathrm{ml}$ of cell culture medium were transfected with $5 \mu \mathrm{g}$ of each of the pMCV1.4-crp1-7 plasmids complexed with $15 \mu$ l of FuGENE HD (Promega, Madison, WI, USA) for $24 \mathrm{~h}$ at 
$22^{\circ} \mathrm{C}$ (transfection efficiency of $15.2-30.4 \%, \mathrm{n}=3$ as estimated by transfection with pMCV1.4-gfp). After

washing with fresh cell culture medium, the ssCRP1-7 were harvested 3-days later, cell debris eliminated by

centrifugation, sterilized by filtration through $0.2 \mu$ filters and kept in aliquots at $-80{ }^{\circ} \mathrm{C}$ until used, essentially

following the previously described procedure [7].

SVCV infection of pre-incubated EPC cell monolayers with 25HOCh and ssCRP1-7

To detect the effects of 25HOCh and ssCRP1-7 (25HOCh + ssCRP1-7) on SVCV infection, the

optimized (not shown). Optimal conditions were obtained when the EPC cell monolayers were pre-incubated

with $100 \mu$ of 4 -fold diluted ssCRP1-7 or ssGFP in RPMI with 2\% FBS in the absence or presence of $10 \mu \mathrm{M}$

$25 \mathrm{HOCh}$ for $20 \mathrm{~h}$ at $26^{\circ} \mathrm{C}$, the monolayers washed twice and SVCV added at $10^{-2}$ m.o.i. To estimate the

extent of SVCV infection, the monolayers were incubated with SVCV for $2 \mathrm{~h}$, washed, and incubated for 24

h at $26^{\circ} \mathrm{C}$. The number of infected EPC cells was estimated by flow cytometry after staining with

monoclonal anti-SVCV (BioX Diagnostics SA, Jemelle, Belgium) and fluorescein-labelled goat anti-mouse

immunoglobulins as described before [7]. The number of EPC infected cells varied from 29.6-39.7 \% or 9.9-

$20.1 \%(n=3)$ after pre-incubation of the EPC cell monolayers with either 25HOCh or ssCRP1-7 alone,

respectively. The results of pre-incubation with $25 \mathrm{HOCh}+$ ssCRP1-7 were expressed in relative percentage of

infection $\pm 25 \mathrm{HOCh}$ as calculated by the formula, $100 \times$ (percentage of infected EPC cells pre-incubated with

25HOCh + CRP1-7 / percentage of infected EPC cells pre-incubated in absence of 25HOCh and presence of

CRP1-7).

\section{In silico modelling of CRP1-7 tridimensional structures}

To explore the CRP1-7 tridimensional structures, their protein sequences were automatically

modelled (RMSD<0.3 $\breve{\text { A }) ~ u s i n g ~ t h e ~ S W I S S-M O D E L ~ h o m o l o g y ~ s e r v e r ~}$

(https://swissmodel.expasy.org/interactive) [39-41]. Tridimensional structures of the target CRP1-7

sequences were predicted after pairwise comparing interfaces between the target and the best template 
resulted selected for the automatical modelling corresponded to zebrafish CRP5 $\pm \mathrm{Ca}++(4 \mathrm{PBP} . \mathrm{pdb}$ and

4PBO.pdb) [6] (RCSB data bank at http://www.rcsb.org/pdb/home/home.do).

\section{Results and discussion}

\section{Preferential docking predictions of zebrafish CRP1-7 to Ch}

To predict their docking $\Delta \mathrm{G}$ energies to CRP1-7, phosphocholine head (PC), other phospholipid

heads [43-45] and cholesterol (Ch) [16] were selected because of their hCRP ligand properties. Interestingly,

the results predicted the lowest $\Delta \mathrm{G}$ (prediction of stronger binding) for $\mathrm{Ch}(\Delta \mathrm{G}$ ranges from -7.5 to -9

$\mathrm{Kcal} / \mathrm{mol}$ ) compared to phospholipid-heads ( $\Delta \mathrm{G}$ ranges from -4 to $-5.5 \mathrm{Kcal} / \mathrm{mol})$. The addition of a glycerol

molecule to those phospholipid-heads did not changed their predicted $\Delta \mathrm{G}$ (not shown). Results also predicted

Ch docking energies more $\mathrm{Ca}^{++}$-independent than most other lipid-heads (Figure 1A), and alternative docking

locations for $\mathrm{Ch}$ and other lipid-heads (not shown).

\section{Membrane Ch sequestering by methyl-betacyclodextrins decreases SVCV infection}

To explore whether Ch was implicated in any anti-viral effects, SVCV infections were studied after

previous treatment of the EPC cell monolayers with methyl-betacyclodextrins (MBCD), a sequestering agent

for membrane Ch. Treatment with MBCD from 0.5 to $8 \mathrm{mM}$ lowered the SVCV infectivity to $20 \%$ (Figure

1B, black line), while those concentrations did not have any significative effects on cell survival (Figure 1B,

blue dashed line). These results confirmed that the $\mathrm{Ch}$ presence in the cell membranes was required for SVCV infectivity and suggest that the CRP1-7-Ch predicted docking may have anti-viral effects. Because, i) Ch-

Ch-related compounds was performed before studying any possible anti-viral effects. 
258 CRP1-7 (Figure 2). The majority of the lowest $\Delta \mathrm{G}$ values were obtained for CRP1 while CRP5 showed

$259 \quad 0.5-1 \mathrm{Kcal} / \mathrm{mol}$ higher $\Delta \mathrm{G}$ than $\mathrm{CRP} 1$, depending on the Ch-related molecule. The most relevant results of 260 these Ch-related docking predictions could be summarized as follows: i) Water-soluble hydroxy Ch

261 derivatives (HOChs) interacted with CRP1-7 within lower $\Delta \mathrm{G}$ ranges $(-8.0$ to $-9 \mathrm{Kcal} / \mathrm{mol})$, ii) Most of the 262 lower $\Delta \mathrm{G}$ values corresponded to CRP1, while most of the highest $\Delta \mathrm{G}$ corresponded to CRP5, and iii) The 263 25-hydroxycholesterol (25HOCh) was unique among the tested HOChs since docking predicted the lowest $\Delta \mathrm{G}$ 264 values $(\sim-9 \mathrm{Kcal} / \mathrm{mol})$.

To explore for the existence of other possible Ch-related compounds with still lower $\Delta \mathrm{G}$ values which could be used as anti-inflammatory chemotherapeutic drugs, a library of 1093 Ch-related synthetic molecules were docked to CRP1-7. The frequency distribution of predicted $\Delta$ Gs showed the existence of Ch-related nonphysiological compounds with lowest $\Delta \mathrm{G}$ values from -13.3 to $-12 \mathrm{Kcal} / \mathrm{mol}(\mathrm{mean}-3 \mathrm{x}$ standard deviations $=$ $12 \mathrm{Kcal} / \mathrm{mol}$ ) (Table 1). Most of the new molecules identified contained Deuterium, Fluorine, Bromine or Chlorine atoms and $66.6 \%$ contained, at least, one hydroxy group per molecule. Therefore, some of these newly identified Ch-related derivatives could be further used for drug applications and/or mechanistic studies in the future.

\section{Binding of zebrafish rCRPs to hydroxycholesterols (HOChs), Ch and PC}

We then tried to confirm some of the docking predictions by solid-phase binding assays. Because activities [24, 47], 25HOCh was compared to $\mathrm{Ch} / \mathrm{PC}$ bindings (the former because containing the traditional ligand for hCRP). Using 25HOCh coated solid-phase polystyrene plates [33], the binding results rCRP7 to Ch / 25HOCh were slightly higher than to rCRP2 or rCRP5 (Figure 3, rCRP7) while rCRP2 / explored the rest of isoforms for binding to 25HOCh using CRP1-7-enriched supernatants from EPC cells 
284 the lower 25HOCh concentrations assayed $(<10 \mu \mathrm{M})$ (Figure 3B). On the other hand, although CRP7

285 showed slightly higher bindings at $>100 \mu \mathrm{M} 25 \mathrm{HOCh}$, similar values were obtained for all ssCRP1-7 at those

286 higher concentrations. Binding of ssCRP1-7 to solid-phase $25 \mathrm{HOCh}$ showed relatively lower values than to

287 rCRPs, most probably due to the lower CRP concentrations in the ssCRP1-7 (compare ordinate values of

288 Figure $3 \mathrm{~A}$ and $\mathrm{B})$.

\section{Mapping of CRP5 binding and docking to 25HOCh}

To further clarify the 25HOCh binding to CRP1-7, we mapped such interaction. Because m-hCRP rather than $\mathrm{p}$-hCRP is the conformation that preferentially binds $\mathrm{Ch}[16,17,48]$, some non-conformational motifs may

conserve Ch- / 25HOCh-binding activity. Therefore, we selected a pepscan to explore for possible non-

conformational interactions with $25 \mathrm{HOCh}$ by solid-phase binding assays and by docking predictions.

For the peptide binding assays, each of the synthetically biotinylated 15-mer peptides derived from the

CRP5 amino acid sequence were incubated with 25HOCh-coated solid-phases. Results showed maximal binding

peaks at the $\sim 30-50,70-90,110-150$ and 170-190 amino acid positions (Figure 4A, black line). Similar peaks

docked with minimal $\Delta \mathrm{G}$ to $25 \mathrm{HOCh}$ (Figure $4 \mathrm{~A}$, blue line). Of the $25 \mathrm{HOCh}$ binding/docking peaks identified,

only the 30-50 was in a similar region than the 35-47 peptide previously identified in hCRP as the main Ch-

binding domain [16]. To locate the predicted interaction of 25HOCh with the CRP1-7 tridimensional structures

we used PyMol. The $25 \mathrm{HOCh}$ docked at the CRP5 interface side with $\Delta \mathrm{G}$ between -7.5 to $-8.4 \mathrm{Kcal} / \mathrm{mol}$ (some

of the contact positions at T41, E48, R71, F84, F85, S117) (Figure 4A, CRP5). In contrast, the 25HOCh

docked at other CRP1-7 effector faces under the $\alpha$-helix with $\Delta \mathrm{G}$ between -8.6 to $-9.1 \mathrm{Kcal} / \mathrm{mol}$ (some of the

contact positions for CRP1 at R113, S115, G153, E154, Y161, and E206) (Figure 4B, CRP1). Similar $\Delta \mathrm{G}$

values and docking location were predicted for m- or t-CRP5 (not shown). Similar docking locations were

predicted for 25HOCh and Ch for most CRP1-7 within $\pm \Delta \mathrm{G}>\sim 0.5 \mathrm{Kcal} / \mathrm{mol}$ (not shown).

between 25HOCh and CRP5 and most probably for all CRP1-7. 
Hydroxylated Chs (HOChs) are Ch oxidized derivatives with diverse biological activities, most of

them correlating with inflammatory responses [49]. Among the HOChs, 25HOCh had minimal $\Delta \mathrm{G}$ docking

311 predictions for CRP1-7 (-8 to $-9 \mathrm{Kcal} / \mathrm{mol}$, corresponding to concentrations between 1.35 to $0.35 \mu \mathrm{M})($ Figure

$3123)$. Among their biological activities, $25 \mathrm{HOCh}$ have been related to viral infections [24, 50], including the

313 reduction of Spring Viremia Carp Virus (SVCV) infection in zebrafish [47]. Because of the Ch-dependence of

314 SVCV infection (Figure 1B), the reduction of SVCV infection by zebrafish ssCRP1-7 [7] was chosen as an

315 example of possible CRP1-7- HOChs interactions affecting the same function.

Because both 25HOCh [47] and CRP1-7 [7] have independent anti-SVCV effects, their

317 concentrations were first titrated at different multiplicities of SVCV infection (m.o.i.) to maximize the limits

318 of detection when they were used together. Under optimal conditions, the extent of SVCV infections

319 (ssCRP1-7 + 25HOCh / ssCRP1-7) were further reduced 1.5 to 3-fold compared to 25HOCh $(\mathrm{GFP}+25 \mathrm{HOCh})$

320 depending on the CRP1-7 isoform (Figure 5A). Similar results were obtained with rCRP5 and rCRP7 but not

321 with rCRP2 (not shown). All the above commented results suggested that 25HOCh in the presence of CRP1-7

322 further enhanced the anti-viral effects caused by either 25HOCh or CRP1-7 alone. It is still too early to know

323 about the mechanisms implicated, since interaction of 25HOCh with the L polymerase of SVCV [47], or

$32425 \mathrm{HOCh}$ inhibition of glycosylation in other rhabdoviruses [51], may suggest that binding to some viral

325 proteins cannot be excluded. Furthermore, other possible interactions between $25 \mathrm{HOCh}, \mathrm{CRP}$ (direct effect)

326 and/or other CRP-induced molecules (indirect effects) present in the ssCRP1-7, may still explain the above

327 mentioned anti-viral enhancements.

328 To explore for any possible correlations among CRP1-7 structures and 25HOCh binding or anti-viral

329 effects, we then studied whether different oligomeric forms were present in the ssCRP1-7 employed for the

330 above mentioned binding and anti-viral experiments.

331 Insect-made rCRPs suggested different oligomerization states

332 E.coli-made zebrafish c-reactive protein CRP5 isoform (rCRP5) crystalized as trimers (t-CRP5) as

333 shown by X-rays [6]. However, it is not yet known whether or not trimers are the physiological form or that

334 is similar for the rest of CRP1-7 isoforms. 
Our first attempts to characterize CRP1-7 isoforms included expression in E.coli. However,

numerous experiments met with irreproducibility, expression failure, high CRP denaturation or low

yields, despite reduction of autoinduction or temperature, and/or re-cloning of the best producing

clones (not shown). Most probably some of those results could be explained by the toxicity of the

rCRPs to E.coli.

Alternatively, we explored production of rCRP1 / rCRP2 / rCRP5 / CRP7 in insect cells.

Results showed that while insect-made rCRP2 / rCRP5 / rCRP7 could be expressed and purified by

non-denaturing affinity chromatography, all attempts to purify rCRP1 were unsuccessful. Western blot

analysis using anti-polyH antibodies indicated that although small amounts of rCRP1 were present, they were

not retained by the affinity columns, most probably due to polyH tail inaccessibility (not shown), perhaps

becuase a different conformation of rCRP1 compared to the other rCRPs.

Polyacrylamide gel electrophoresis (PAGE) in the absence of SDS in the buffers, treating the samples

under non-denaturing conditions (no heat, no SDS, no ß-mercaptoethanol and $1 \mathrm{mM} \mathrm{CaCl}_{2}$ ), and Western

blotting with anti-p3 antibodies, showed that rCRP2 (calculated isoelectric point IP of 6.35) banded at an

apparent M.W. of > $100 \mathrm{KDa}$, while rCRP5 (IP 4.6) and rCRP7 (IP 4.6) banded at $75 \mathrm{KDa}$ (Figure 1A left).

A brief ( $2 \mathrm{~min}$ ) treatment of the rCRP samples under denaturing conditions, increased the migration of all rCRP, specially that of rCRP7 (Figure 1A right). Although in the absence of SDS, the estimation of molecular weights is not accurate, the results may suggest larger sizes for rCRP2 / rCRP5 compared to rCRP7, according to previous electrophoretic data described for $\mathrm{p}$-hCRP and m-hCRP [52].

In contrast, by applying PAGE in the presence of SDS in the buffers, samples under non-denaturing conditions and Western blotting, all the rCRP displayed similar bands which could be interpreted as residual amounts of trimers $(\sim 75 \mathrm{KDa})$, dimers $(\sim 50 \mathrm{KDa})$ and monomers $(\sim 25 \mathrm{KDa})$ (Figure $6 \mathrm{~B}$, left). The amount of 
360 different positions of the monomeric forms could be most probably due to differences in their glycosylation,

361 although recently different post-transcriptional deimidation has been also described in cod CRPs [53].

362 The most probable explanation for all the above commented data suggests that while insect-made

$363 \mathrm{rCRP} 2 / \mathrm{rCRP} 5$ may exist as an equilibrium among trimers, dimers and monomers, rCRP7 has a stronger

364 tendency to form monomers.

365 CRP1-7-enriched supernatants from EPC cell transfected cells appeared monomeric

Western blotting of ssCRP1-7 using anti-p3 antibodies, only detected CRP2-7 monomers of $\sim 25$ KDa

with slightly different positions for each ssCRP2-7, with similar profiles under denaturing (Figure 6C, down),

20-fold lower SDS concentration (not shown)[54] and non-denaturing (not shown) sample and buffer conditions.

Similar CRP2-7 levels were present in ssCRP2-7 as shown using actin as an internal marker (Figure 6C, up). In

these experiments, it was not possible to detect the presence of any CRP1 band, most probably because its lower

concentration, since previous results demonstrated its presence by dot-blot when using concentrated ssCRP1 [7].

Most probably, all ssCRP1-7 were secreted from EPC transfected cells mainly as monomers.

\section{In silico predictions of zebrafish CRP1-7 tridimensional structures}

To obtain more data on the possible structures of CRP1-7, their amino acid sequences were modelled

using the SWISS-MODEL web program. Automatic modelling showed that only CRP2 / CRP5 rendered

trimers, while the rest of the CRP1-7 modelled as monomers only (Table 2). CRP2 / CRP5 have differences

in most of the modelling parameters, specially in their torsion-angle potentials, compared to other CRP1-7

(Table 2). Because the existence of $\sim 70$ EST from zebrafish in the UniGene Bank classified as CRP5

transcript variants [6] offered another opportunity to test the reliability of the trimer/monomer predictions 
transcript variants to oligomerize as trimers and prompt for further studies about the biological

387 significance for both CRP isoforms and variants.

The PAGE/Western data and the in silico predictions, together with the results of 25HOCh binding

(Figure 3A) and enhancement of anti-SVCV effects (Figure 5A) by ssCRP1-7, may implicate more the m-

CRP1-7 rather than t-CRP1-7 in those functions. However, CRP1-7 may also physiologically exist as an

equilibrium of trimers, dimers and monomers, as shown in the cases of CRP2 /CRP5 and to lower extent in

CRP7. On the other hand, because m-hCRP can also be produced in vitro, for instance by treatments with urea, low-pH or low-salt buffers in the absence of $\mathrm{Ca}^{++}[54,55]$, the m-CRP1-7 detected in this work may

have been produced by the in vitro manipulations (i.e., purification by affinity chromatography in the absence of $\mathrm{Ca}^{++}$, transfection of EPC cells, etc). We may also speculate that t-CRP1-7 could preferentially exist in fish until an stimulus triggers their conversion to m-CRP1-7 or viceversa since circulating hCRP is pentameric (p-hCRP) [13] and converts to monomeric (m-hCRP) after interaction with exposed

The t-CRP1-7 may be functionally analogous to the circulating p-hCRP and the m-CRP1-7 could be analogous to the converted m-hCRP. Alternatively, zebrafish m-CRP1-7 may be synthesized de novo as of those possibilities remain speculative until specific reagents could be developed. 
412 Table 1.

413 Ch-related non-physiological compounds with best docking predictions to CRP1-7

414

\begin{tabular}{rllr}
\multicolumn{1}{c}{ ID } & Name & \multicolumn{2}{c}{$\Delta \mathbf{G}}$, \\
\hline 71749935 & M Progesterone-d3 Glucuronide & Kcal/mol \\
70626502 & $25-F-1 \alpha-H O C h$ & $\operatorname{crp} 5$ & -13.3 \\
71749934 & M Progesterone Glucuronide & crp5 & -13.3 \\
70626891 & diF-methyl-dodecahydro-cyclopentaphenanthrene & crp1 & -13.3 \\
493972 & F-11-HO-Methyl-DioxoPregnadien-Acetate & crp5 & -12.6 \\
192154 & triFlumedroxone Acetate & crp5 & -12.6 \\
240767 & Fmetholone 17 Acetate & crp5 & -12.5 \\
95574 & F-16a,17-(isopropylidenedioxy) Corticosterone & crp5 & -12.5 \\
71748935 & 20-HOCh-d7 & crp5 & -12.4 \\
21122966 & 6-HO-M Progesterone 17-Acetate & crp5 & -12.3 \\
102276261 & 3-[(2-B-ethyl)Carbamoyl]Ch & crp5 & -12.3 \\
71749110 & HO-M Progesterone 17-Acetate & crp5 & -12.2 \\
71748841 & 4-7 HOcholestenone-d7 & crp1 & -12.1 \\
57357615 & 17-(Acetyloxy)-C-(C-methyl)Pregnadienedione & crp5 & -12.1 \\
126456352 & 24-HOCh-d4 & crp1 & -12.1 \\
71748930 & 4-HOCh-d7 4-Acetate & crp5 & -12.1 \\
71315435 & Cortexone M-d9 & crp1 & -12.1 \\
10476437 & Flugestone 17-Acetate & crp5 & -12 \\
71315435 & Cortexone M-d9 & crp5 & -12 \\
71315434 & Cortexone M-d8 & crp1 & -12 \\
71315434 & Cortexone M-d8 & crp5 & -12 \\
\hline
\end{tabular}

415

416

417

418

419

420

421

422

423

424

425

426

427

428

429

430

Ch-related non-physiological compound structures were retrieved from several libraries obtained from PubChem in a *.sdf format. To construct the library, 550 Chs, 314 Colestens, 73 Corticosterones, 41 Dehydroepiandrosterones (DHEAs), 107 Estriols, 99 Pregnenolones, 196 Progesterones and 107 HOChs were retrieved. Duplicated and extremely long molecules were eliminated from the total of $1487{ }^{*}$.sdf, resulting in a downsized library of $1093^{*}$.pdbqt archives. After docking, the frequency distribution of $\Delta \mathrm{G}$ showed two peaks with means at -11 and $-7 \mathrm{Kcal} / \mathrm{mol}$, respectively. Only those Ch-related compounds with $\Delta \mathrm{G}<-12$ $\mathrm{Kcal} / \mathrm{mol}$ (mean $+3 \mathrm{x}$ standard deviations) were tabulated. ID, PubMed number. Red bold HO, Hydroxy. Red bold d, deuterium. Red bold F, fluoro-. Red bold C, chloro-. Red bold B, Bromo. Red bold M, 17acetyl-6,10,13-trimethyl-3-oxo-1,2,6,7,8,9,11,12,14,15,16,17-dodeca HOcyclopenta[a]phenanthren-16-yl) acetate (Medroxy). 
432 Table 2

433 Parameter values of in silico predicted CRP1-7 oligomeric structures

\begin{tabular}{|c|c|c|c|c|c|c|c|}
\hline isoform & Acc.number & $\begin{array}{r}\text { Automatic SWISS } \\
\text { prediction }\end{array}$ & QMEAN & $\mathrm{CB}$ & $\mathbf{A A}$ & SO & TO \\
\hline CRP1 & XM_693995.4 & monomer & -0.55 & -1.36 & -1.03 & -1.03 & 0.01 \\
\hline CRP2 & ВC097160 & homo-trimer & 0.77 & -1.64 & -1.08 & -0.92 & 1.19 \\
\hline CRP3 & BC154042 & monomer & 0.01 & -1.15 & -1.15 & -1.03 & 0.51 \\
\hline CRP4 & BC115188 & monomer & -1.81 & -1.65 & -1.95 & -1.33 & -1.07 \\
\hline CRP5 & BC121777 & homo-trimer & 1.42 & -0.71 & -0.89 & -0.60 & 1.62 \\
\hline $\begin{array}{l}\text { CRP5 } \\
47 \text { variants }\end{array}$ & $\begin{array}{l}\text { Dr.124528- } \\
\text { Dr.162306 }\end{array}$ & $\begin{array}{r}97.8 \% \\
\text { homo-trimers }\end{array}$ & $\begin{array}{r}1.12 \\
\pm 0.31\end{array}$ & $\begin{array}{r}-\mathbf{0 . 9 0} \\
\pm 0.5\end{array}$ & $\begin{array}{r}\mathbf{- 0 . 9 9} \\
\pm 0.2\end{array}$ & $\begin{array}{r}\mathbf{- 0 . 6 8} \\
\pm 0.4\end{array}$ & $\begin{array}{l}1.30 \\
\pm 0.5\end{array}$ \\
\hline CRP6 & BC162745 & monomer & -0.45 & -1.20 & -1.17 & -1.34 & 0.15 \\
\hline CRP7 & BC150371 & monomer & -0.42 & -1.04 & -1.22 & -1.28 & 0.15 \\
\hline
\end{tabular}

434

The CRP1-7 amino acid sequences [2] were modelled as tridimensional structures using the SWISS-MODEL server with automatic template selection. In addition, 47 full-length CRP5 amino acid sequences were modelled from 73 zebrafish crp5 EST variants (UniGene Dr.124528-Dr.162306) [6]. QMEAN, estimation of total similarity to the template, made up of 4 individual Z-score parameters (Cß, all-atom, solvation and torsion). The individual Z-scores compare the predicted tridimensional structures with template by: i) $\mathrm{C} \beta$ atoms of three consecutive amino acids $(\mathbf{C B})$, ii) all-atoms (AA), iii) solvation burial status of the residues (SO) and iv) torsion angle potentials (TO). Low QMEAN score values indicate low similarity to the template. High QMEAN score values indicate high similarity to the template. Bold, highest and/or lowest score values. Gray, CRP2 / CRP5. The mean \pm standard deviation $(n=47)$ of the calculated score values of the CRP5 transcript variants were represented. 
451 Figure 1. CRP1-7 preferential docking to Ch (A) and inhibition of SVCV infectivity by methyl-

452 betacyclodextrin (MBCD) (B)

453 A) Docking predictions to selected lipid-heads and Ch. The CRP1-7 were SWISS-modelled using as

454 templates the CRP5 (GenBank accession number JF772178.1), 4PBP.pdb (+Ca $\left.\mathbf{a}^{++}\right)$and 4PBO.pdb (-Ca $\left.{ }^{++}\right)$

455 3D-structures [6]. Structures were extracted from *.sdf from PubChem

456 (https://pubchem.ncbi.nlm.nih.gov/search/search.cgi) and converted to *.pdbqt using the Babel program from

457 the PyRx package [27]. $\Delta \mathrm{G}$ values from two independent dockings were averaged, the standard deviations

458 ( $<5 \%)$ omitted for clarity. PC, Phosphocholine. PE, Phosphoethanolamine. PS, Phosphoserine. SPG,

459 palmitoyl sphingomyelin. Ch, cholesterol. Numbers before the names_, PubMed ID numbers. Blue open

460 circles, consecutive CRP1-7 isoforms from left to right in the absence of $\mathrm{Ca}^{++}$. Black open circles,

461 consecutive CRP1-7 isoforms from left to right in the presence of $\mathrm{Ca}^{++}$. Red circles, CRP5. Black lines,

$462+\mathrm{Ca}^{++}$. Dot lines, $-\mathrm{Ca}^{++}$. B) Effect of methyl-betacyclodextrin (MBCD) on SVCV infectivity. MBCD-treated

463 EPC cell monolayers were incubated with SVCV for $24 \mathrm{~h}$ and assayed by ffu. The results were expressed as

464 infectivity percentages calculated by the formula, $100 \times$ (ffu treated with MBCD / ffu non-treated with

465 MBCD). To assay for viability, MBCD-treated EPC cell monolayers were incubated with MTT for $3 \mathrm{~h}$,

466 absorbance at $570 \mathrm{~nm}$ measured and the percentage of viability calculated by the formula, absorbance of

467 treated cells / absorbance of untreated cells. Open blue or black circles and their vertical lines, means and

468 standard deviations $(\mathrm{n}=2)$, respectively. The data were then interpolated and smoothed by the cubic B-spline

469 method in Origin Pro 2017 (Northampton, MA, USA). Black line, SVCV infectivity. Blue dashed line, EPC

470 cell monolayer viability.

472 Figure 2. CRP1-7 docking predictions to several Ch-related physiological molecules

473 CRP1-7 models, Ch-related physiological molecules and $\Delta \mathrm{G}$ predictions were obtained as described in the

474 legend of Figure 3. Because the predicted $\Delta \mathrm{G}$ values in the absence or presence of $\mathrm{Ca}^{++}$were similar, only

475 the mean $\Delta \mathrm{Gs} \pm \mathrm{Ca}^{++}$were represented. Open circles, consecutive CRP1-7 isoforms from left to right. Red

476 circles, CRP5. Numbers before the names_, PubMed ID numbers. HO, hydroxy. Ch, cholesterol. 
Figure 3. rCRP (A) and ssCRP1-7 (B) binding to solid-phase lipids.

479

480

481

482

483

484

485

486

487

488

489

490

491

492

493

494

495

496

497

498

499

500

501

502

Binding of purified rCRPs and ssCRP1-7 to selected lipids were assayed by using solid-phase plates of 96-well

(Nunc, Maxisorb) coated to dryness with several lipid concentrations dissolved in ethanol. The lipid-coated plates were washed with $0.1 \mathrm{M}$ sodium borate, $1 \mathrm{mM} \mathrm{Ca}_{2} \mathrm{Cl} \mathrm{pH} 8$ (borate buffer) and incubated with rCRP2 or ssCRP1-7 in borate buffer for $1 \mathrm{~h}$ in $50 \mu \mathrm{l}$ volume. To detect bound rCRP or ssCRP1-7, rabbit anti-CRP p3 peptide, peroxidase labeled goat anti-rabbit IgG and OPD were used as described before [34, 35]. Means and standard deviations from 2 independent experiments $(n=2)$ were represented. A) rCRP at $0.5 \mu \mathrm{g} /$ well in borate buffer. Open triangles, solid-phase phosphatidylcholine (PC). Open circles, solid-phase Ch. Black circles, solid-phase 25HOCh. B) ssCRP1-7 were 10-fold diluted in borate buffer. Means (n=6) were interpolated and smoothed by the cubic B-spline method in Origin Pro 2017 (Northampton, MA, USA). Black points, supernatant from pMCV1.4-gfp transfected cells. Blue line, supernatant from pMCV1.4-crpl transfected cells. Green line, supernatant from pMCV1.4-crp2 transfected cells. Light-blue line, supernatant from pMCV1.4-crp3 transfected cells. Gray line, supernatant from pMCV1.4-crp4 transfected cells. Red line, supernatant from pMCV1.4-crp5 transfected cells. Orange line, supernatant from pMCV1.4-crp6 transfected cells. Purple line, supernatant from pMCV1.4-crp7 transfected cells.

\section{Figure 4. Solid-phase binding and docking predictions to 25HOCh of CRP5 pepscan peptides (A) and}

\section{predicted best docking location (B)}

A) For the peptide-binding assays, a series of 15-mer peptides overlapping 5 amino acids from CRP5 were chemically synthesized by adding an amino-terminal biotin molecule. Solid-phases were coated with $2 \mu \mathrm{g}$ per well of $25 \mathrm{HOCh}$ into polystyrene $96-w e l l$ plates. Binding of $0.05 \mu \mathrm{g}$ biotinylated pepscan peptides, detection with peroxidase-labelled streptavidin and staining with OPD were then performed. Means from 2 independent experiments were represented, standard deviations omitted for clarity. For the in silico docking predictions, the modelled pepscan peptides with the lowest energies were docked to several possible conformations of $25 \mathrm{HOCh}$ as described in methods. The docking energies which best fitted the binding data were then represented. Black 
line, peptide binding to $25 \mathrm{HOCh}$. Blue line, predicted $\Delta \mathrm{G}$ energy of peptide docking to $25 \mathrm{HOCh}$. B) PyMOL

504 representation of the lowest energy structures of CRP5 and CRP1 complexed to 25HOCh (the rest of CRP1-7

505 were similar). Green, CRP amino acid chains. Red, 25HOCh. Blue circles, $\mathrm{Ca}^{++}$atoms located at the PC-

506 binding pocket [6].

Figure 5. Anti-SVCV infectivity after treatment of EPC cell monolayers with 25HOCh and CRP1-7.

A) EPC cell monolayers were incubated with $100 \mu 1$ of ssGFP or ssCRP1-7 4-fold diluted in RPMI with 2\% $\mathrm{FBS} \pm 10 \mu \mathrm{M} 25 \mathrm{HOCh}$ for $20 \mathrm{~h}$ at $26^{\circ} \mathrm{C}$. After washing, $10^{-2} \mathrm{~m} . \mathrm{o} . \mathrm{i}$ of SVCV were added and incubated for $24 \mathrm{~h}$. After staining with anti-SVCV and fluorescein-labelled goat anti-mouse immunoglobulins [7], the number of fluorescent cells were estimated by flow cytometry. B) representative aspect of histograms from non-fluorescent and fluorescent cells. The number of SVCV infected EPC cells varied from 12.7 to $50.6 \%$ $(n=5)$, depending on the experiment. The results were expressed as relative infection percentages calculated by the formula, $100 \mathrm{x}$ (number of infected cells $+25 \mathrm{HOCh} /$ number of infected cells $-25 \mathrm{HOCh}$ ). Means and standard deviations of a representative experiment were represented $(n=3) . *$, statistically $<$ than cells transfected with ssGFP at $\mathrm{p}<0.05$ (Student t-test). ssCRP1-7 (D).

The insect-made affinity purified samples were electrophoresed in 4-20\% gradient of polyacrylamide gels.

A) Samples of rCRPs prepared and electrophoresed in the absence of SDS in the buffers and stained with mercaptoethanol and SDS, electrophoresed in the presence of SDS in the buffers (denaturing conditions) and stained with Coomassie. C) Western blotting of the gel B transferred to nitrocellulose membranes, stained with anti-p3 antibody, horseradish peroxidase labelled anti-rabbit and over-exposed to diaminobenzidine (DAB) [34]. The ssCRP1-7 were electrophoresed in $15 \%$ polyacrylamide gels . D) Samples of ssCRP1-7 
529 the buffers, transferred to nitrocellulose membranes, stained with anti-actin (up) or anti-p3 (down)

530 antibody, horseradish peroxidase labelled anti-rabbit and developed by chemiluminiscence [7]. Similar

531 results were obtained with samples electrophoresed under non-denaturing conditions (not shown). Numbers

532 around the gels, molecular weight markers in KDa. Up left arrow, position recognized by anti-actin

533 antibodies. Down left arrow, position of purified rCRP5 recognized by anti-p3 antibodies. Results are

534 representative of at least 3 experiments.

Figure 7. Alignement among EST-derived amino acid sequences of CRP5 transcript variants

537 Transcript variants corresponding to the zebrafish crp5 gene were retrieved from 73 EST obtained from

538 different zebrafish tissues (UniGene Dr.124528-Dr.162306) [6]. The corresponding ORFs $>100$ amino acids

539 translated by the Virtual Ribosome software (http://www.cbs.dtu.dk/services/VirtualRibosome/) were

540 numbered without signal peptide ( ${ }^{\mathrm{F} K N L} .$. in CRP5) and aligned to CRP5 (BC121777). The number of

541 different amino acids per position were represented. The data were smoothed by the cubic B-spline method

542 (Origin Pro 2017, Northampton, MA, USA). Blue circles, Cysteines. Blue rectangle, PC-binding pocket of

543 hCRP. Green rectangles, Ch-binding residues of hCRP [16]. Black line, number of amino acids per

544 position of CRP1-7. Red profile, number of amino acids per position of CRP5 transcript variants. 


\section{List of abbreviations}

554 BSA, bovine serum albumin. CRP, C-reactive protein. Ig, immunoglobulin. KDa, kilo Daltons. MW,

555 molecular weight. PAGE, polyacrylamide gel electrophoresis. PBS, phosphate buffered saline. pfu, plaque

556 forming units. SDS, sodium dodecyl sulfate. SVCV, spring viremia carp virus. VHSV, Viral

557 haemorrhagic septicemia virus. EPC, cell line.

558 Competing interests

559 The authors declare not to have any competing interests

560 Authors' contribution

$561 \mathrm{MB}$ and AF performed the SVCV infections and westerns. JA revised the docking predictions. BN and LP

562 collaborated in the designing of the experiments and reviewed the manuscript. JC designed and analyzed

563 experiments, coordinate the work and drafted the manuscript. All authors read and approved the manuscript.

\section{Acknowledgements}

565

566

567

568

569

570

571

Thanks are due to Paula Perez Gonzalez who helped with the experimentation. Melissa Bello-Perez

was financed by the Generalidad Valenciana, fellowship ACIF/2016. This work was supported by CICYT

projects AGL2014-51773-C3-R and BIO2017-82851 of the Ministerio de Economía, Industria y Competitividad of Spain.

\section{References}

1. Bottazzi B, Inforzato A, Messa M, Barbagallo M, Magrini E, Garlanda C, et al. The pentraxins PTX3 and SAP in innate immunity, regulation of inflammation and tissue remodelling. J Hepatol.

2016;64(6):1416-27. Epub 2016/02/28. doi: S0168-8278(16)00163-X [pii] 10.1016/j.jhep.2016.02.029. PubMed PMID: 26921689.

2. Falco A, Cartwright JR, Wiegertjes GF, Hoole D. Molecular characterization and expression analysis of two new C-reactive protein genes from common carp (Cyprinus carpio). Dev Comp Immunol. 2012;37(1):127-38. Epub 2011/11/15. doi: S0145-305X(11)00278-3 [pii] 10.1016/j.dci.2011.10.005. PubMed PMID: 22079493.

3. Wang J, Tang B, Liu X, Wu X, Wang H, Xu D, et al. Increased monomeric CRP levels in acute myocardial infarction: a possible new and specific biomarker for diagnosis and severity assessment of 
disease. Atherosclerosis. 2015;239(2):343-9. doi: 10.1016/j.atherosclerosis.2015.01.024. PubMed PMID: 25682033.

4. Braig D, Nero TL, Koch HG, Kaiser B, Wang X, Thiele JR, et al. Transitional changes in the CRP structure lead to the exposure of proinflammatory binding sites. Nature communications. 2017;8:14188.

Epub 2017/01/24. doi: ncomms14188 [pii] 10.1038/ncomms14188. PubMed PMID: 28112148.

5. McFadyen JD, Kiefer J, Braig D, Loseff-Silver J, Potempa LA, Eisenhardt SU, et al. Dissociation of C-Reactive Protein Localizes and Amplifies Inflammation: Evidence for a Direct Biological Role of CReactive Protein and Its Conformational Changes. Front Immunol. 2018;9:1351. doi:

10.3389/fimmu.2018.01351. PubMed PMID: 29946323; PubMed Central PMCID: PMCPMC6005900.

6. Chen R, Qi J, Yuan H, Wu Y, Hu W, Xia C. Crystal structures for short-chain pentraxin from zebrafish demonstrate a cyclic trimer with new recognition and effector faces. J Struct Biol.

2015;189(3):259-68. Epub 2015/01/17. doi: S1047-8477(15)00002-7 [pii] 10.1016/j.jsb.2015.01.001. PubMed PMID: 25592778.

7. Bello-Perez M, Falco A, Medina-Gali R, Pereiro P, Encinar JA, Novoa B, et al. Neutralization of viral infectivity by zebrafish c-reactive protein isoforms. Mol Immunol. 2017;91:145-55. doi: 10.1016/j.molimm.2017.09.005. PubMed PMID: 28915434.

8. Inforzato A, Doni A, Barajon I, Leone R, Garlanda C, Bottazzi B, et al. PTX3 as a paradigm for the interaction of pentraxins with the complement system. Semin Immunol. 2013;25(1):79-85. Epub

2013/06/12. doi: S1044-5323(13)00031-6 [pii] 10.1016/j.smim.2013.05.002. PubMed PMID: 23747040.

9. Vilahur G, Badimon L. Biological actions of pentraxins. Vascul Pharmacol. 2015;73:38-44. Epub 2015/05/13. doi: S1537-1891(15)00084-1 [pii]

10.1016/j.vph.2015.05.001. PubMed PMID: 25962566.

10. Caprio V, Badimon L, Di Napoli M, Fang WH, Ferris GR, Guo B, et al. pCRP-mCRP Dissociation Mechanisms as Potential Targets for the Development of Small-Molecule Anti-Inflammatory Chemotherapeutics. Front Immunol. 2018;9:1089. doi: 10.3389/fimmu.2018.01089. PubMed PMID: 29892284; PubMed Central PMCID: PMCPMC5985513.

11. Bang R, Marnell L, Mold C, Stein MP, Clos KT, Chivington-Buck C, et al. Analysis of binding sites in human C-reactive protein for Fc $\{$ gamma $\}$ RI, Fc $\{$ gamma $\}$ RIIA, and C1q by site-directed mutagenesis. J Biol Chem. 2005;280(26):25095-102. Epub 2005/05/10. doi: M504782200 [pii] 10.1074/jbc.M504782200. PubMed PMID: 15878871.

12. Lu J, Marjon KD, Mold C, Du Clos TW, Sun PD. Pentraxins and Fc receptors. Immunol Rev. 2012;250(1):230-8. Epub 2012/10/11. doi: 10.1111/j.1600-065X.2012.01162.x. PubMed PMID: 23046133; PubMed Central PMCID: PMC3471383.

13. Wu Y, Potempa LA, El Kebir D, Filep JG. C-reactive protein and inflammation: conformational changes affect function. Biol Chem. 2015;396(11):1181-97. Epub 2015/06/04. doi: 10.1515/hsz-2015-0149 /j/bchm.just-accepted/hsz-2015-0149/hsz-2015-0149.xml [pii]. PubMed PMID: 26040008.

14. Eisenhardt SU, Habersberger J, Peter K. Monomeric C-reactive protein generation on activated platelets: the missing link between inflammation and atherothrombotic risk. Trends Cardiovasc Med. 2009;19(7):232-7. doi: 10.1016/j.tcm.2010.02.002. PubMed PMID: 20382347.

15. Eisenhardt SU, Thiele JR, Bannasch H, Stark GB, Peter K. C-reactive protein: how conformational changes influence inflammatory properties. Cell Cycle. 2009;8(23):3885-92. doi: 10.4161/cc.8.23.10068. PubMed PMID: 19887916.

16. Li HY, Wang J, Meng F, Jia ZK, Su Y, Bai QF, et al. An Intrinsically Disordered Motif Mediates Diverse Actions of Monomeric C-reactive Protein. J Biol Chem. 2016;291(16):8795-804. doi: 10.1074/jbc.M115.695023. PubMed PMID: 26907682; PubMed Central PMCID: PMCPMC4861447. 17. Wang MY, Ji SR, Bai CJ, El Kebir D, Li HY, Shi JM, et al. A redox switch in C-reactive protein modulates activation of endothelial cells. FASEB J. 2011;25(9):3186-96. doi: 10.1096/fj.11-182741. PubMed PMID: 21670067. 
18. Lv JM, Lu SQ, Liu ZP, Zhang J, Gao BX, Yao ZY, et al. Conformational folding and disulfide bonding drive distinct stages of protein structure formation. Sci Rep. 2018;8(1):1494. doi: 10.1038/s41598018-20014-y. PubMed PMID: 29367639; PubMed Central PMCID: PMCPMC5784126.

19. Bello M, Falco A, Medina R, Encinar JA, Novoa B, Perez L, et al. Structure and functionalities of the human c-reactive protein compared to the zebrafish multigene family of c-reactive-like proteins. Developmental \& Comparative Immunology. 2017;69:33-40.

20. Estepa A, Coll JM. Innate multigene family memories are implicated in the viral-survivor zebrafish phenotype. Plos One. 2015;10(8):e0135483. doi: doi:10.1371/journal.pone.0135483.

21. Garcia-Valtanen P, Martinez-Lopez A, Lopez-Munoz A, Bello-Perez M, Medina-Gali RM, OrtegaVillaizan MD, et al. Zebra Fish Lacking Adaptive Immunity Acquire an Antiviral Alert State Characterized by Upregulated Gene Expression of Apoptosis, Multigene Families, and Interferon-Related Genes. Front Immunol. 2017;8:121. doi: 10.3389/fimmu.2017.00121. PubMed PMID: 28243233; PubMed Central PMCID: PMCPMC5303895.

22. Widziolek M, Prajsnar TK, Tazzyman S, Stafford GP, Potempa J, Murdoch C. Zebrafish as a new model to study effects of periodontal pathogens on cardiovascular diseases. Sci Rep. 2016;6:36023. doi: 10.1038/srep36023. PubMed PMID: 27777406; PubMed Central PMCID: PMCPMC5078774.

23. Zieden B, Kaminskas A, Kristenson M, Kucinskiene Z, Vessby B, Olsson AG, et al. Increased plasma 7 beta-hydroxycholesterol concentrations in a population with a high risk for cardiovascular disease. Arterioscler Thromb Vasc Biol. 1999;19(4):967-71. PubMed PMID: 10195924.

24. Dong H, Zhou L, Ge X, Guo X, Han J, Yang H. Antiviral effect of 25-hydroxycholesterol against porcine reproductive and respiratory syndrome virus in vitro. Antivir Ther. 2018. doi: 10.3851/IMP3232. PubMed PMID: 29561734.

25. Yang J, Gustavsson AL, Haraldsson M, Karlsson G, Norberg T, Baltzer L. High-affinity recognition of the human C-reactive protein independent of phosphocholine. Org Biomol Chem. 2017;15(21):4644-54. doi: 10.1039/c7ob00684e. PubMed PMID: 28513744.

26. Trott O, Olson AJ. AutoDock Vina: improving the speed and accuracy of docking with a new scoring function, efficient optimization, and multithreading. J Comput Chem. 2010;31(2):455-61. doi: 10.1002/jcc.21334. PubMed PMID: 19499576; PubMed Central PMCID: PMCPMC3041641.

27. Dallakyan S, Olson AJ. Small-molecule library screening by docking with PyRx. Methods Mol Biol. 2015;1263:243-50. doi: 10.1007/978-1-4939-2269-7_19. PubMed PMID: 25618350.

28. Shityakov S, Forster C. In silico predictive model to determine vector-mediated transport properties for the blood-brain barrier choline transporter. Adv Appl Bioinform Chem. 2014;7:23-36. doi: 10.2147/AABC.S63749. PubMed PMID: 25214795; PubMed Central PMCID: PMCPMC4159400.

29. Fijan N, Petrinec Z, Sulimanovic D, Zwillenberg LO. Isolation of the viral causative agent from the acute form of infectious dropsy of carp. Veterinary Archives. 1971;41:125-38.

30. ICTV. Implementation of taxon-wide non-Latinized binomial species names in the family Rhabdoviridae. Rhabdoviridae Study Group. 2015:9.

31. Perez-Filgueira DM, Resino-Talavan P, Cubillos C, Angulo I, Barderas MG, Barcena J, et al. Development of a low-cost, insect larvae-derived recombinant subunit vaccine against RHDV. Virology. 2007;364:422-30.

32. Smith PK, Krohn RI, Hermanson GT, Mallia AK, Gartner FH, Provenzano MD, et al. Measurement of protein using bicinchoninic acid. Anal Biochem. 1985;150(1):76-85. Epub 1985/10/01. doi: 00032697(85)90442-7 [pii]. PubMed PMID: 3843705.

33. Biro A, Cervenak L, Balogh A, Lorincz A, Uray K, Horvath A, et al. Novel anti-cholesterol monoclonal immunoglobulin $\mathrm{G}$ antibodies as probes and potential modulators of membrane raft-dependent immune functions. J Lipid Res. 2007;48(1):19-29. doi: 10.1194/jlr.M600158-JLR200. PubMed PMID: 17023738 .

34. Torrent F, Villena A, Lee PA, Fuchs W, Bergmann SM, Coll JM. The amino-terminal domain of ORF149 of koi herpesvirus is preferentially targeted by IgM from carp populations surviving infection. Arch Virol. 2016;161(10):2653-65. doi: 10.1007/s00705-016-2934-4. PubMed PMID: 27383208. 
35. Coll JM. Herpesvirus infection induces both specific and hetrologous anti-viral antibodies in carp. Frontiers in Immunology. 2018;9. doi: doi: 10.3389/fimmu.2018.00039.

36. Neron B, Menager H, Maufrais C, Joly N, Maupetit J, Letort S, et al. Mobyle: a new full web bioinformatics framework. Bioinformatics. 2009;25(22):3005-11. doi: 10.1093/bioinformatics/btp493. PubMed PMID: 19689959; PubMed Central PMCID: PMCPMC2773253.

37. Estepa A, Coll JM. Pepscan mapping and fusion related properties of the major phosphatidylserinebinding domain of the glycoprotein of viral hemorrhagic septicemia virus, a salmonid rhabdovirus. Virology. 1996;216:60-70.

38. Estepa AM, Rocha AI, Mas V, Perez L, Encinar JA, Nunez E, et al. A protein G fragment from the Salmonid viral hemorrhagic septicemia rhabdovirus induces cell-to-cell fusion and membrane phosphatidylserine translocation at low pH. Journal of Biological Chemistry. 2001;276(49):46268-75. PubMed PMID: ISI:000172573100106.

39. Biasini M, Bienert S, Waterhouse A, Arnold K, Studer G, Schmidt T, et al. SWISS-MODEL: modelling protein tertiary and quaternary structure using evolutionary information. Nucleic Acids Res. 2014;42(Web Server issue):W252-8. doi: 10.1093/nar/gku340. PubMed PMID: 24782522; PubMed Central PMCID: PMCPMC4086089.

40. Arnold K, Bordoli L, Kopp J, Schwede T. The SWISS-MODEL workspace: a web-based environment for protein structure homology modelling. Bioinformatics. 2006;22(2):195-201. doi: 10.1093/bioinformatics/bti770. PubMed PMID: 16301204.

41. Guex N, Peitsch MC. SWISS-MODEL and the Swiss-PdbViewer: an environment for comparative protein modeling. Electrophoresis. 1997;18(15):2714-23. doi: 10.1002/elps.1150181505. PubMed PMID: 9504803.

42. Mariani V, Kiefer F, Schmidt T, Haas J, Schwede T. Assessment of template based protein structure predictions in CASP9. Proteins. 2011;79 Suppl 10:37-58. doi: 10.1002/prot.23177. PubMed PMID: 22002823.

43. Tanaka T, Robey FA. A new sensitive assay for the calcium-dependent binding of C-reactive protein to phosphorylcholine. J Immunol Methods. 1983;65(3):333-41. PubMed PMID: 6361145. 44. Pepys MB. C-reactive protein fifty years on. Lancet. 1981;1(8221):653-7. PubMed PMID: 6110874.

45. Agrawal A, Xu Y, Ansardi D, Macon KJ, Volanakis JE. Probing the phosphocholine-binding site of human C-reactive protein by site-directed mutagenesis. J Biol Chem. 1992;267(35):25353-8. Epub 1992/12/15. PubMed PMID: 1460031.

46. Yang Q, Zhang Q, Tang J, Feng WH. Lipid rafts both in cellular membrane and viral envelope are critical for PRRSV efficient infection. Virology. 2015;484:170-80. doi: 10.1016/j.virol.2015.06.005. PubMed PMID: 26115164.

47. Pereiro P, Forn-Cuni G, Dios S, Coll J, Figueras A, Novoa B. Interferon-independent antiviral activity of 25-hydroxycholesterol in a teleost fish. Antiviral Res. 2017;145:146-59. doi: 10.1016/j.antiviral.2017.08.003. PubMed PMID: 28789986.

48. Ji SR, Wu Y, Zhu L, Potempa LA, Sheng FL, Lu W, et al. Cell membranes and liposomes dissociate C-reactive protein (CRP) to form a new, biologically active structural intermediate: $\mathrm{mCRP}(\mathrm{m})$. FASEB J. 2007;21(1):284-94. doi: 10.1096/fj.06-6722com. PubMed PMID: 17116742.

49. Gold ES, Diercks AH, Podolsky I, Podyminogin RL, Askovich PS, Treuting PM, et al. 25Hydroxycholesterol acts as an amplifier of inflammatory signaling. Proc Natl Acad Sci U S A. 2014;111(29):10666-71. doi: 10.1073/pnas.1404271111. PubMed PMID: 24994901; PubMed Central PMCID: PMCPMC4115544.

50. Civra A, Cagno V, Donalisio M, Biasi F, Leonarduzzi G, Poli G, et al. Inhibition of pathogenic nonenveloped viruses by 25-hydroxycholesterol and 27-hydroxycholesterol. Sci Rep. 2014;4:7487. doi: 10.1038/srep07487. PubMed PMID: 25501851; PubMed Central PMCID: PMCPMC4265783. 51. Shrivastava-Ranjan P, Bergeron E, Chakrabarti AK, Albarino CG, Flint M, Nichol ST, et al. 25Hydroxycholesterol Inhibition of Lassa Virus Infection through Aberrant GP1 Glycosylation. mBio. 
2016;7(6). doi: 10.1128/mBio.01808-16. PubMed PMID: 27999160; PubMed Central PMCID: PMCPMC5181775.

52. Potempa LA, Yao ZY, Ji SR, Filep JG, Wu Y. Solubilization and purification of recombinant modified C-reactive protein from inclusion bodies using reversible anhydride modification. Biophys Rep. 2015;1:18-33. doi: 10.1007/s41048-015-0003-2. PubMed PMID: 26942216; PubMed Central PMCID: PMCPMC4762138.

53. Magnadottir B, Hayes P, Gisladottir B, Bragason B, Hristova M, Nicholas AP, et al. Pentraxins CRP-I and CRP-II are post-translationally deiminated and differ in tissue specificity in cod (Gadus morhua L.) ontogeny. Dev Comp Immunol. 2018;87:1-11. doi: 10.1016/j.dci.2018.05.014. PubMed PMID: 29777721.

54. Taylor KE, van den Berg CW. Structural and functional comparison of native pentameric, denatured monomeric and biotinylated C-reactive protein. Immunology. 2007;120(3):404-11. doi: 10.1111/j.1365-2567.2006.02516.x. PubMed PMID: 17163961; PubMed Central PMCID: PMCPMC2265887.

55. Potempa LA, Maldonado BA, Laurent P, Zemel ES, Gewurz H. Antigenic, electrophoretic and binding alterations of human C-reactive protein modified selectively in the absence of calcium. Mol Immunol. 1983;20(11):1165-75. PubMed PMID: 6656768. 
A

B
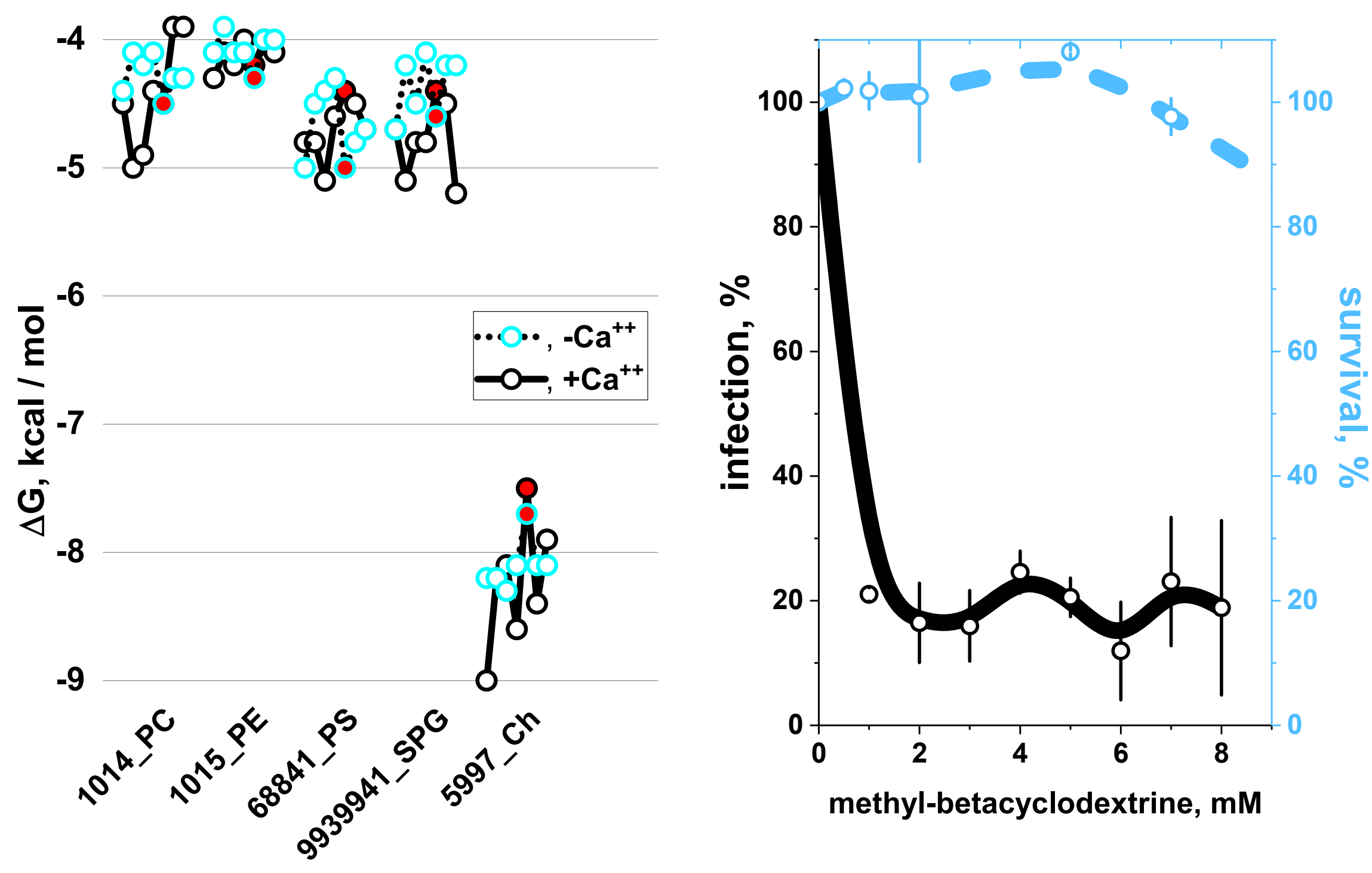

Figure 1 


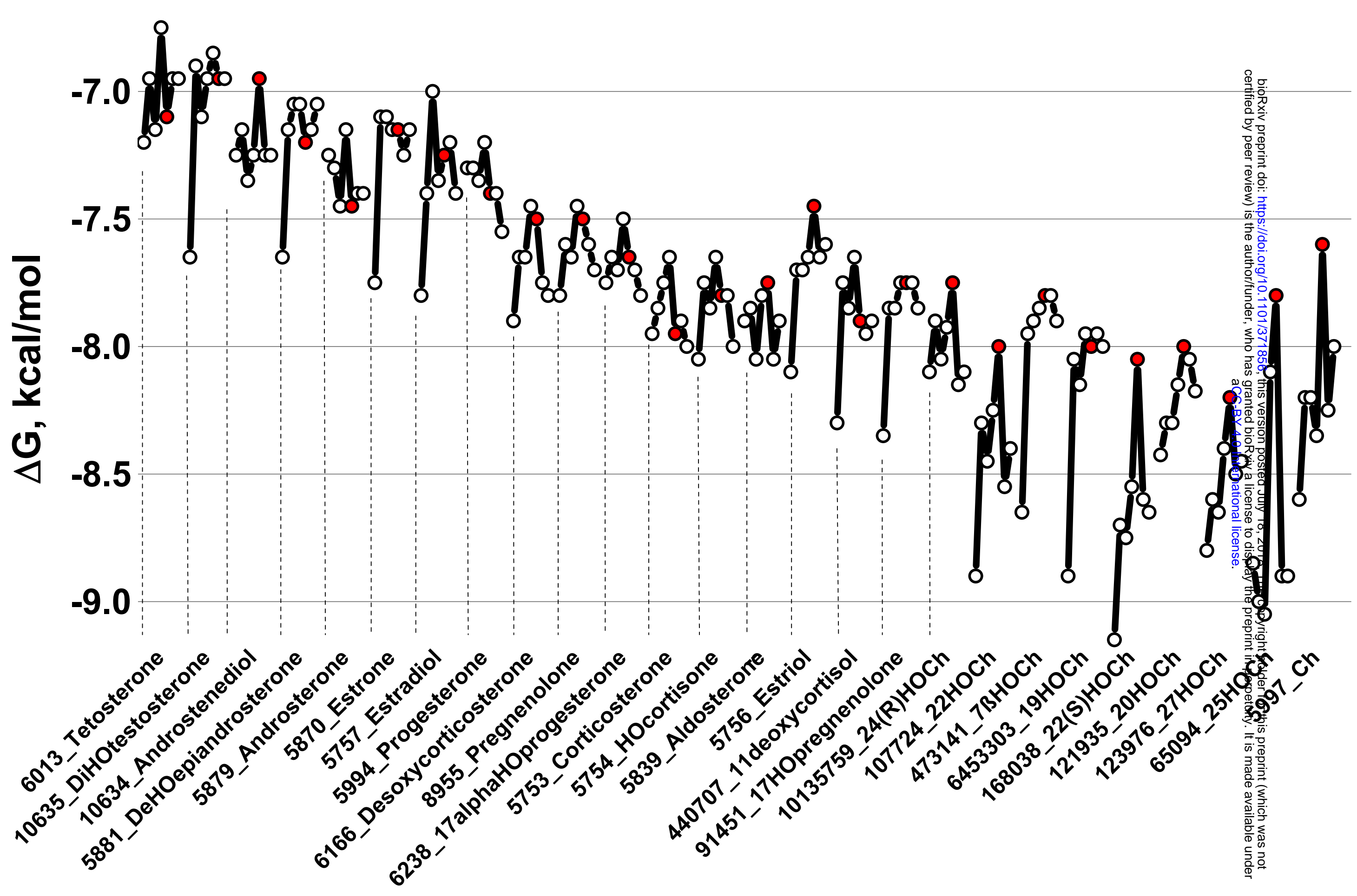

Figure 2 

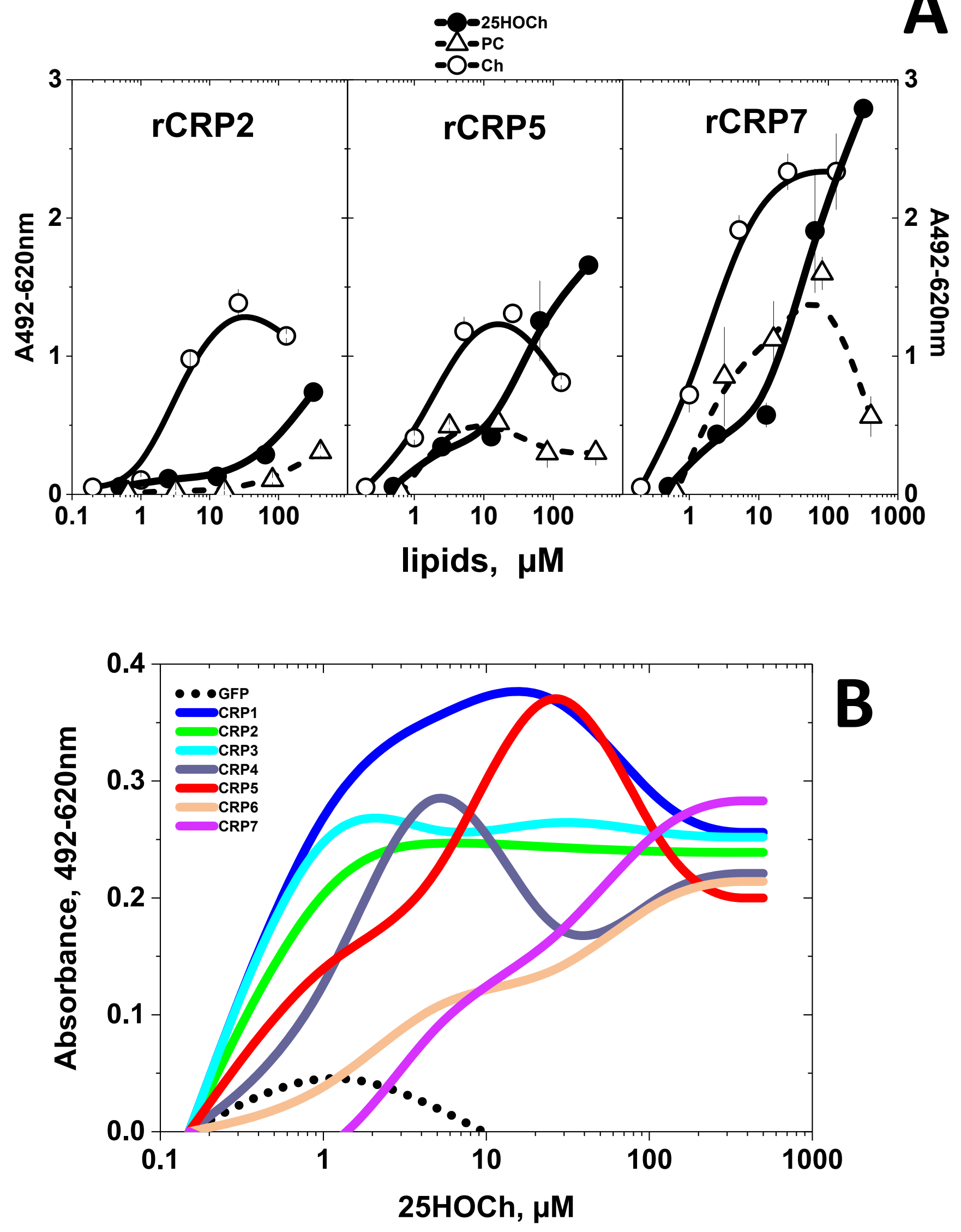

Figure 3 
bioRxiv preprint doi: https://doi.org/10.1101/371856; this version posted July 18, 2018. The copyright holder for this preprint (which was not certified by peer review) is the author/funder, who has granted bioRxiv a license to display the preprint in perpetuity. It is made available under aCC-BY 4.0 International license.

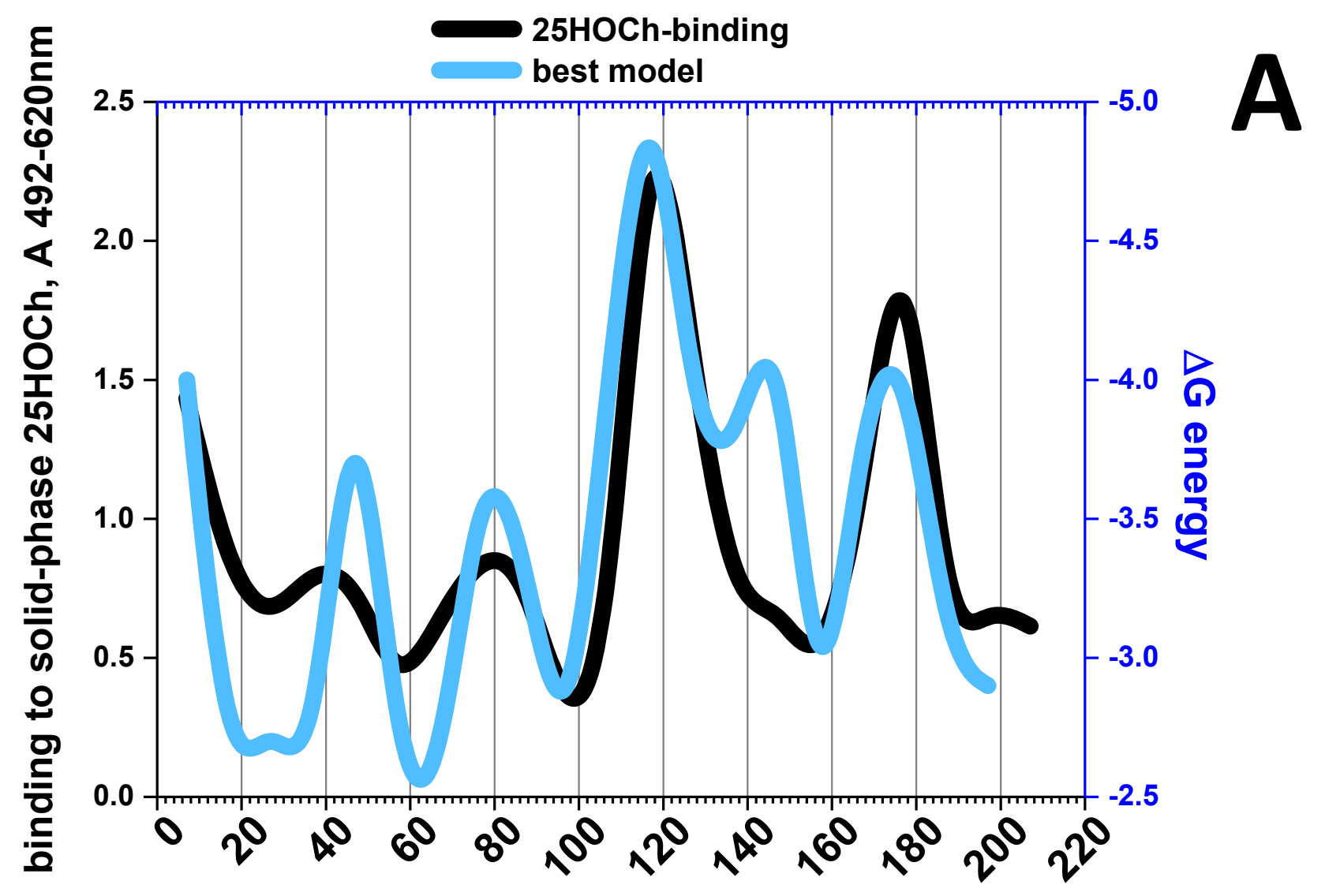

CRP5 15-mer pepscan, amino acid number
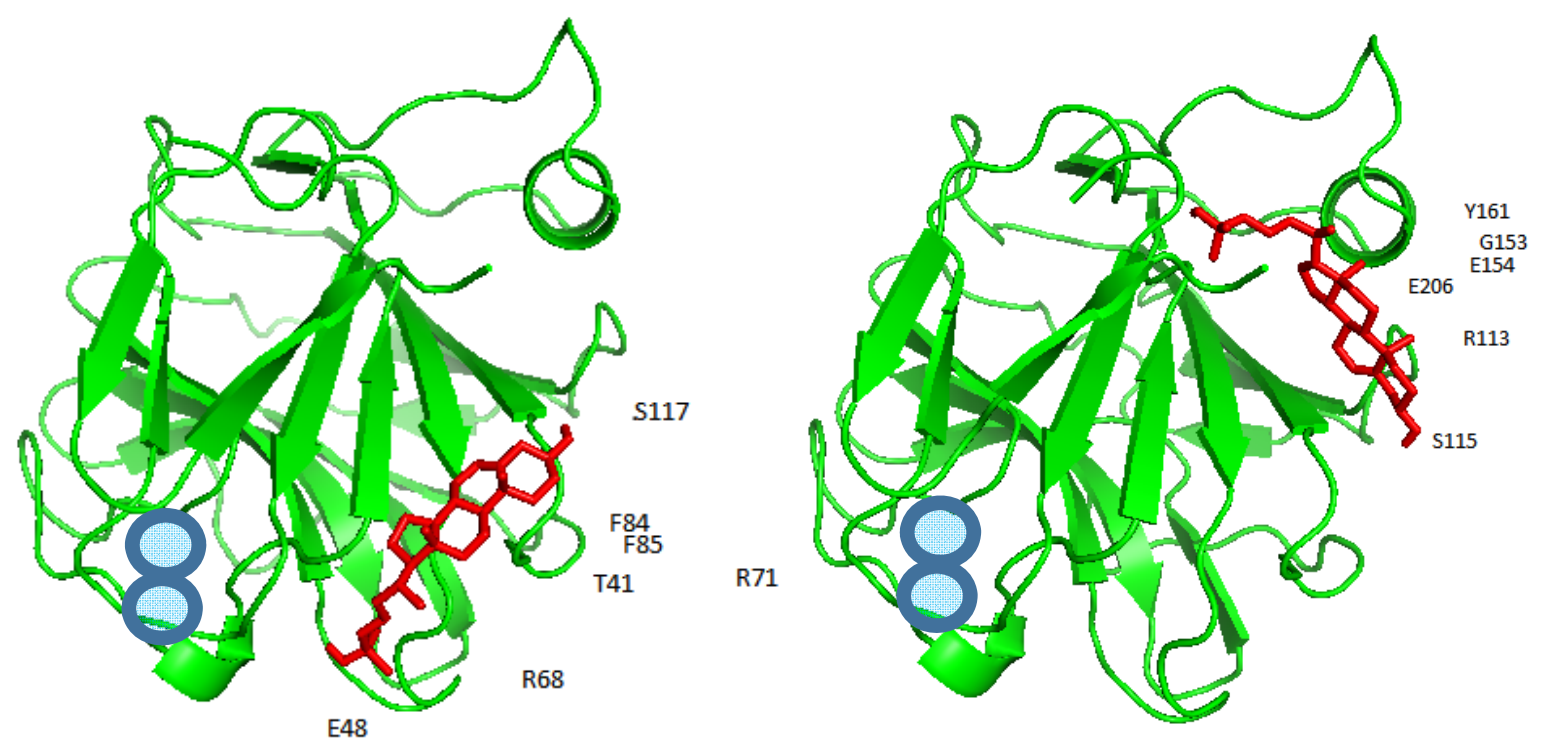

CRP5

CRP1

Figure 4 


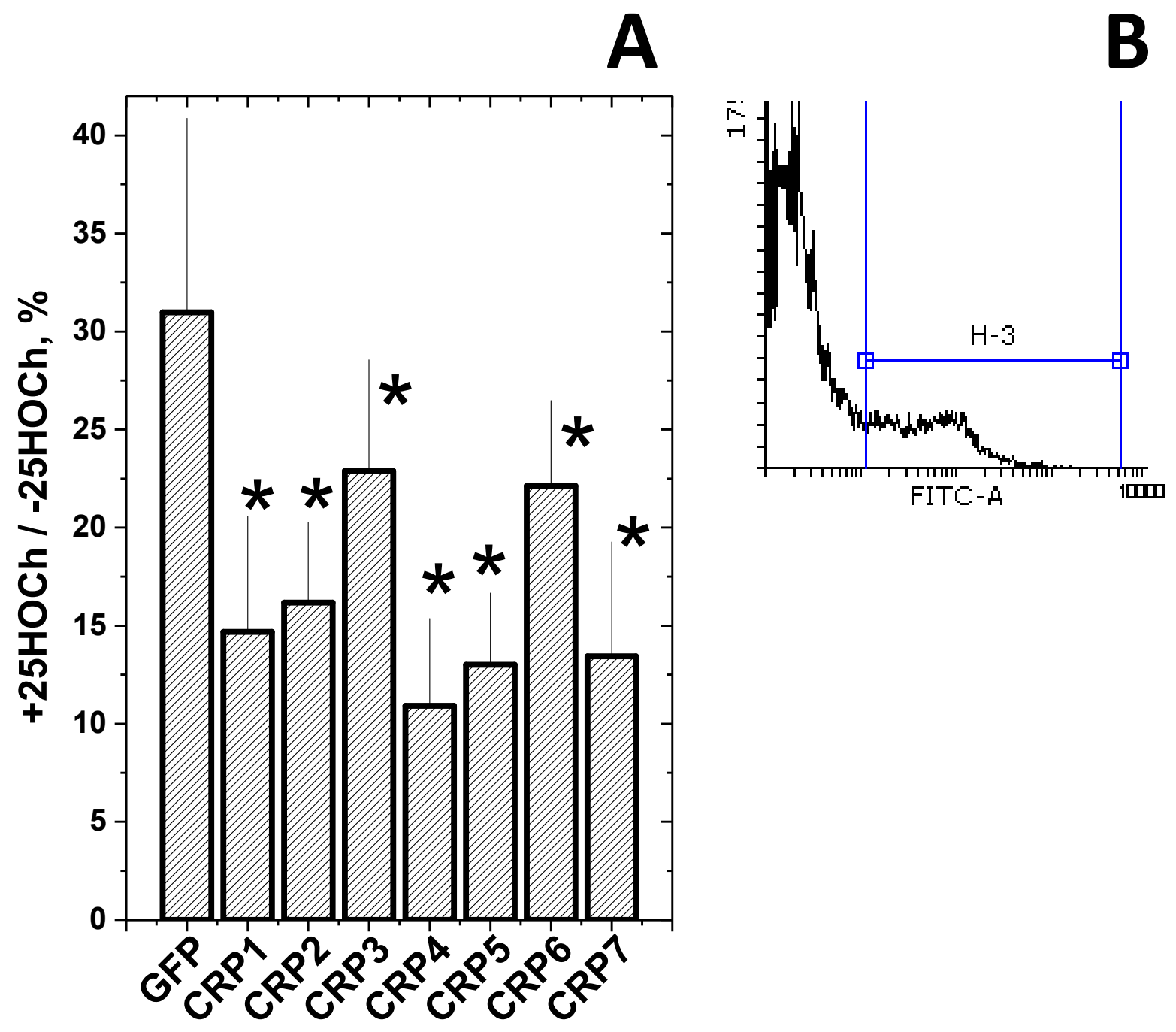

Figure 5 
bioRxiv preprint doi: https://doi.org/10.1101/371856; this version posted July 18, 2018. The copyright holder for this preprint (which was not certified by peer review) is the author/funder, who has granted bioRxiv a license to display the preprint in perpetuity. It is made available $\mathrm{dunder}$

\section{Gel-SDS}

$\begin{array}{ll}\text { No heat } & \text { +heat } \\ \text { No SDS } & \text { +SDS } \\ \text { No Bmer } & + \text { +ßmer } \\ +1 \mathrm{mMCa}+ & \end{array}$

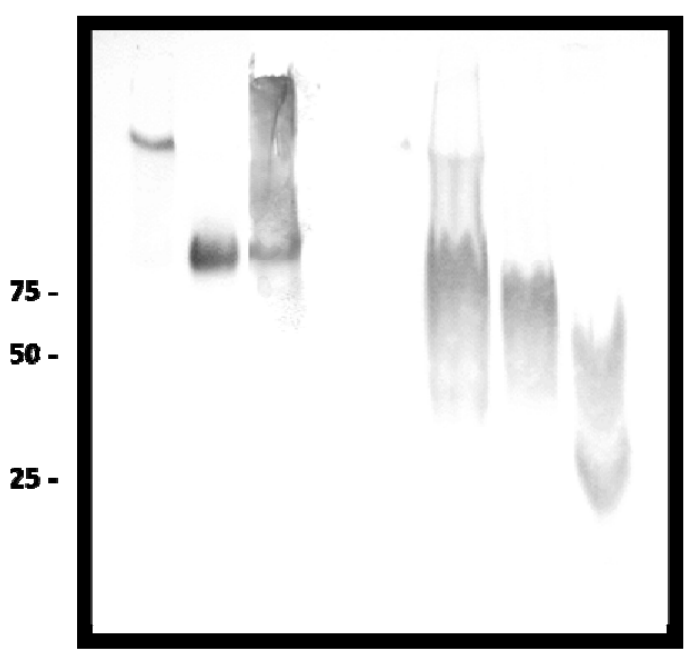

257

257

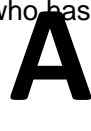

aCC-BY 4.0 International license.

\section{Gel+SDS}

$\begin{array}{lll}\text { No heat } & \text { low heat } & \text { +heat } \\ \text { No SDS } & \text { +SDS } & \text { +SDS } \\ \text { No Bmer } & \text { +ßmer } & + \text { \&mer }\end{array}$

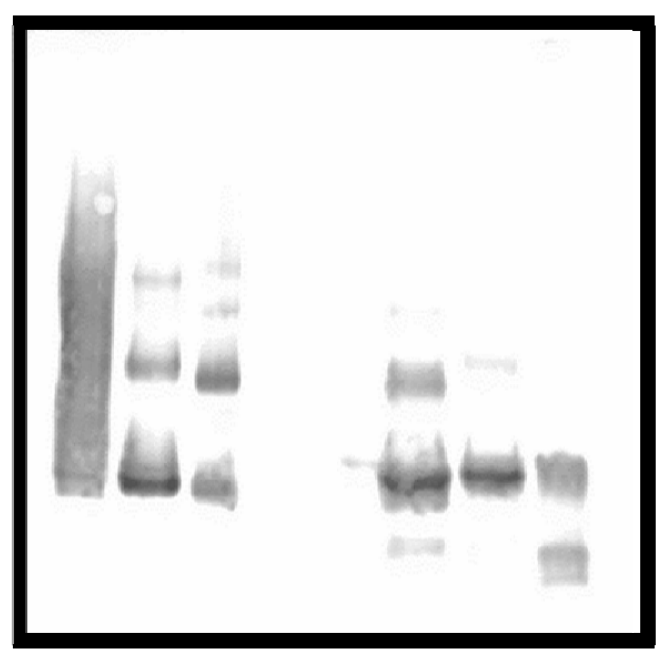

$\begin{array}{lll}2 & 5 & 7\end{array}$

$\begin{array}{lll}2 & 5 & 7\end{array}$

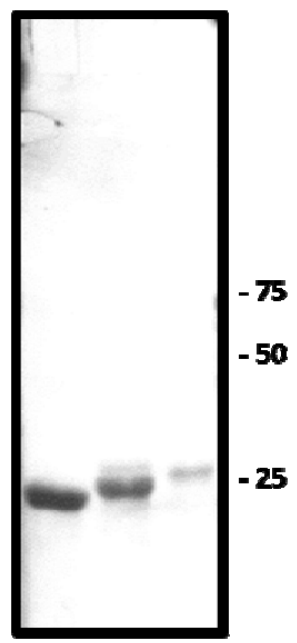

$\begin{array}{lll}2 & 5 & 7\end{array}$

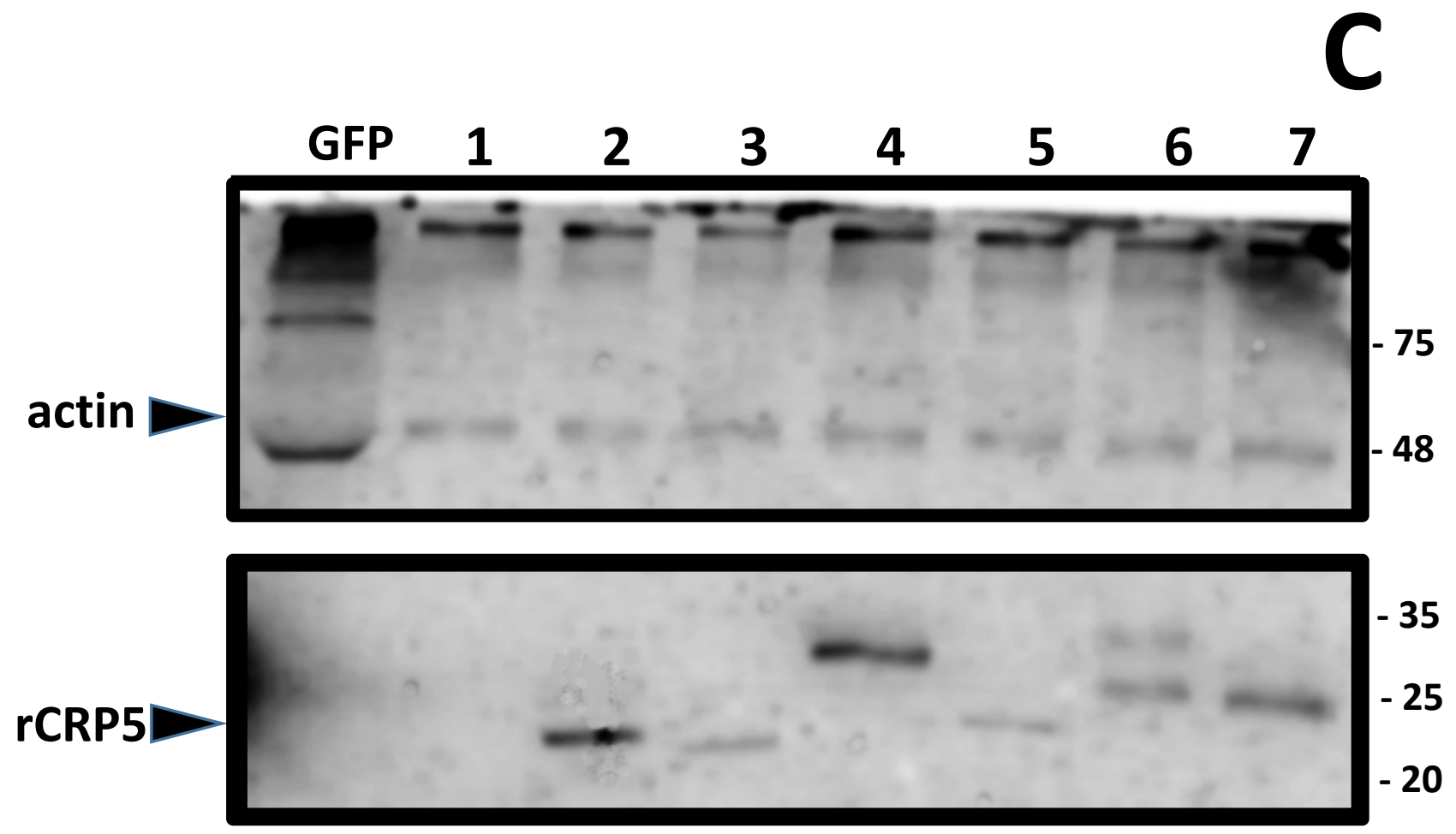

Figure 6 
